\title{
DIAGNÓSTICO DAS EMISSÕES ATMOSFÉRICAS DE ORIGEM VEICULAR NA ÁREA URBANA DE CAMPO MOURÃO - PR.
}

\author{
R.F. SILVA ${ }^{1}$ J. H. B. ARAÚJO², G. G. TEIXEIRA ${ }^{3}$, G. R. N. MEIRA ${ }^{4}$ \\ ${ }^{1}$ Universidade Tecnológica Federal do Paraná - Campus Campo Mourão, \\ Departamento Acadêmico de Ambiental \\ ${ }^{2}$ Universidade Tecnológica Federal do Paraná - Campus Campo Mourão, \\ Departamento Acadêmico de Ambiental \\ ${ }^{3}$ Universidade Tecnológica Federal do Paraná - Campus Campo Mourão, \\ Departamento Acadêmico de Ambiental \\ ${ }^{4}$ Universidade Tecnológica Federal do Paraná - Campus Campo Mourão, \\ Departamento Acadêmico de Ambiental \\ E-mail para contato: jaraujo@utfpr.edu.br
}

\begin{abstract}
RESUMO - Com o aumento tecnológico e das áreas urbanizadas muito tem sido discutido sobre as emissões atmosféricas geradas nesse contexto. As emissões veiculares prejudicam a qualidade do ar, afetando todos os seres vivos. O objetivo deste trabalho foi monitorar a qualidade do ar em quatro pontos distintos distribuídos pela malha urbana da cidade de Campo Mourão - PR, visando à verificação dos níveis de poluição. As amostragens das concentrações de poluentes emitidos por fontes móveis foram realizadas com um aparelho portátil medidor de gases $\left(\mathrm{CO}, \mathrm{H}_{2} \mathrm{~S}\right.$, gases combustíveis voláteis). Apesar de verificarem-se alguns picos de medições de monóxido de carbono com valores acima dos estabelecidos pela Resolução CONAMA 03/1990, a qualidade do ar de Campo Mourão - PR pode ser considerada boa. A quantidade de veículos que circularam durante as medições não foi o fator determinante na emissão dos poluentes, no entanto, veículos antigos e as condições climáticas podem ter influenciado nos resultados.
\end{abstract}

\section{INTRODUÇÃO}

O homem modifica cada vez mais o espaço natural para atender suas necessidades produzindo cada vez mais impactos, o que acaba afetando na qualidade de vida da população tanto nas grandes quanto nas pequenas cidades. O desenvolvimento urbano altera os ambientes naturais, causando efeitos negativos sobre o mesmo. $\mathrm{O}$ intenso processo de urbanização ocorrido nas últimas décadas apresenta consequências de ordem social e ambiental. Aspectos como o lançamento de poluentes no ar, solo e água, caracterizam-se como agentes degradantes da qualidade ambiental e da qualidade de vida da população. Dentre as inúmeras formas de degradações ambientais verificadas no meio urbano, a poluição atmosférica, apresenta-se como um dos principais fatores de rebaixamento da qualidade de vida e ambiental, por caracterizar-se como poluição difusa e atingir pontos adjacentes ao seu lançamento, esta afeta de maneira direta o ser humano, ocasionando eventuais transtornos à saúde pública. A poluição do ar é 
determinada por um complexo sistema de fontes emissoras (fontes móveis e fontes fixas), as emissões de origem veicular (fontes móveis) são responsáveis por boa parte desses lançamentos. Comumente discute-se a questão da poluição atmosférica por veículos automotores nas grandes cidades, devidos a seus volumosos congestionamentos e grande número de veículos, deixando-se de lado esses fatores nas pequenas e médias cidades brasileiras (MAZOLI, 2009). O monitoramento da qualidade do ar tem relevada importância para a definição de políticas de abatimento da poluição atmosférica. É através da rede de monitoramento que se pode constatar a evolução das concentrações dos poluentes e aferir a eficácia dos processos de controle de emissões. $\mathrm{O}$ objetivo deste trabalho é realizar um diagnóstico sobre a poluição atmosférica de origem veicular em quatro pontos distintos na cidade de Campo Mourão - PR, utilizando analisador portátil de gases, comparando os valores obtidos nas medições com os padrões exigidos pela resolução CONAMA nº 3 de 28 de junho de 1990.

\section{METODOLOGIA}

Este estudo foi desenvolvido na cidade de Campo Mourão - PR, que apresenta uma população de 91.648 mil habitantes (IBGE, 2013). Apresenta clima subtropical com temperatura média de $18^{\circ} \mathrm{C}$ no mês mais frio e acima de $22^{\circ} \mathrm{C}$ no mês mais quente, com verões quentes, geadas pouco frequentes e tendência de concentração das chuvas nos meses de verão, sem estação seca definida. A cobertura vegetal nativa é o bioma Mata Atlântica, com pequenas porções de Cerrado. Está localizado no terceiro planalto paranaense, com relevo variando de suavemente ondulado a ondulado, propiciando a utilização da agricultura mecanizada. A malha urbana está localizada em sua grande maioria em relevo suavemente ondulado propiciando também o processo de urbanização da cidade.

Anteriormente à expansão da malha urbana de Campo Mourão a partir da década de 1950, a vegetação da cidade era composta por um ecótono entre Floresta Estacional Semidecidual e Floresta Ombrófila Mista Montana. A Floresta Ombrófila Mista Montana ou Floresta com Araucária é uma unidade fitoecológica com a coexistência de representantes das floras tropical e temperada. Compreende as formações florestais típicas e exclusivas dos planaltos da região sul do Brasil, com disjunções na região sudeste e em países vizinhos (Paraguai e Argentina). Pelas suas características climatológicas, descritas anteriormente, Campo Mourão possui fatores favoráveis para a dispersão de seus poluentes, como clima quente e úmido em uma grande parte do ano.

As medições foram realizadas de 25 a 28 de novembro de 2013 e do dia 18 a 21 de fevereiro de 2014 em quatro locais (pontos) distintos na área urbana da cidade, designados como Ponto A, Ponto B, Ponto C e Ponto D (Figura 1). As coletas dos dados foram planejadas para obter dados em duas estações diferentes (primavera e verão). Na primavera a intensidade dos raios solares é menor se comparado ao verão e no verão os dias são mais longos prolongando o período de exposição solar e consequentemente à elevação da temperatura, item fundamental na dispersão dos poluentes. Foram realizadas aferições três vezes ao dia com duração de uma hora cada, sendo dois dias para cada ponto. Os pontos foram selecionados na cidade por contemplarem diferentes situações em relação à circulação de veículos e pedestres, além da geografia do local. 


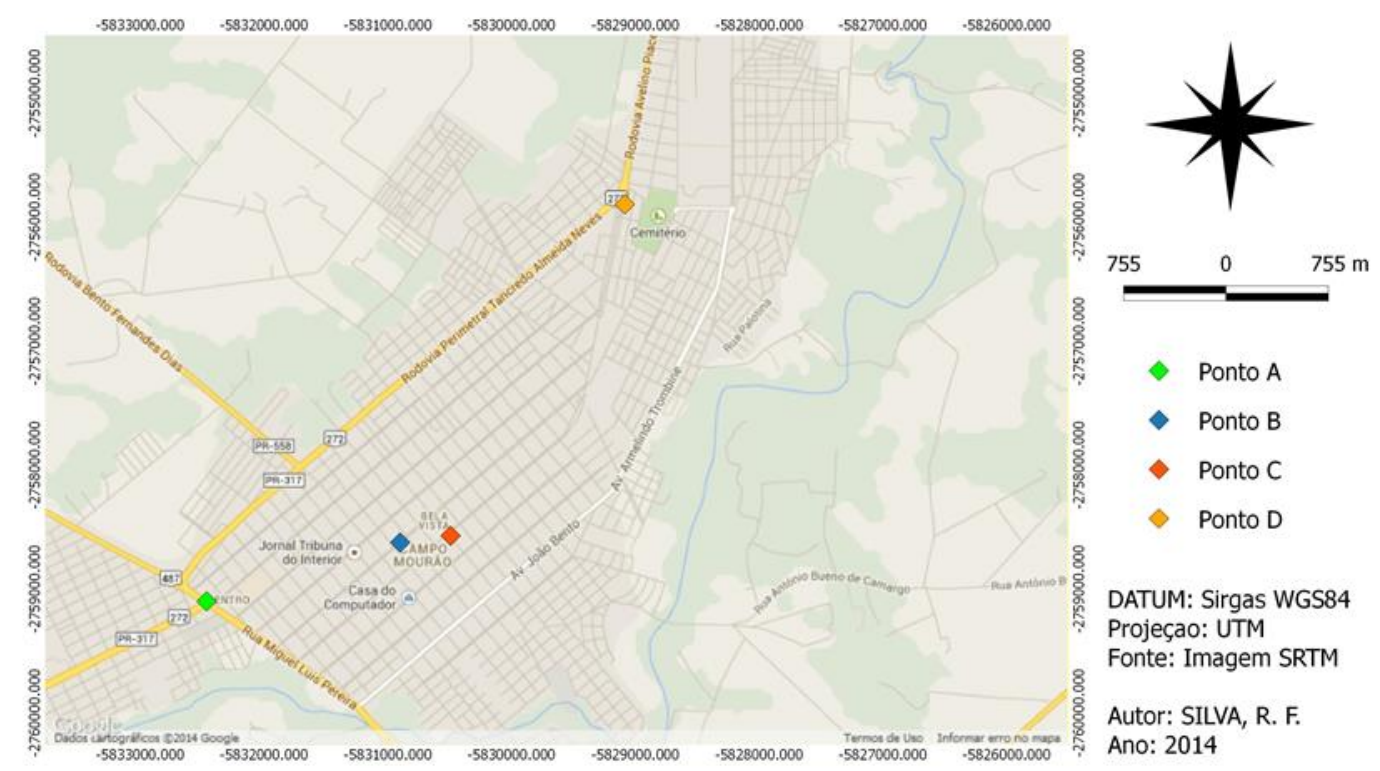

Figura 1 - Distribuição dos pontos de amostragem na malha urbana de Campo Mourão $-\mathrm{PR}$.

As coletas de dados foram realizadas durante os horários de picos, das $07 \mathrm{~h} 00$ às $08 \mathrm{~h} 00,12 \mathrm{~h} 00$ às $13 \mathrm{~h} 00$ e $17 \mathrm{~h} 00$ às $18 \mathrm{~h} 00$. Os veículos que trafegavam nesses locais eram contabilizados em uma planilha e classificados em: motocicletas, veículos leves (automóveis e utilitários de pequeno porte) e veículos pesados (camionetas, caminhonetes cabine simples e dupla, veículos SUV - Sport Utility Vehicles, ônibus, caminhões, bitrens). Para detectar e quantificar as concentrações dos gases poluentes utilizou-se o equipamento detector de gás portátil, modelo Gas Alert MAX XT II, fabricado por BW Technologies, que registra a concentração dos seguintes poluentes: $\mathrm{H}_{2} \mathrm{~S}$ (ppm), $\mathrm{CO}$ (ppm), $\mathrm{O}_{2}(\%)$ e gases combustíveis (\%). O equipamento ficou a uma altura (distância do solo) de aproximadamente 1,5 metros nos pontos e períodos de medição. Os valores de $\mathrm{CO}$ detectados durante os 60 minutos de monitoramento foram somados, realizando posteriormente o calculo da média horária, assim os valores de CO apresentados neste trabalho estão de acordo com os dispostos na resolução CONAMA $\mathrm{n}^{\text {o }} 3$ de 28 de junho de 1990. Para aferir a temperatura instantânea $\left(\mathrm{C}^{\circ}\right)$ e umidade relativa do ar (\%) foi utilizado outro aparelho portátil, modelo Instrutherm CO2. Com esses dados é possível traçar um plano de melhoria do sistema rodoviário da cidade, para reduzir os efeitos da poluição, principalmente nos pontos abordados, além de sugestões para reduzir o fluxo nos horários de pico ou na realização de campanhas de transito para o uso de transportes coletivos, melhoria dos carros, renovação da frota, uso de meios de transporte menos poluentes, entre outros.

\section{RESULTADOS E DISCUSSÃO}

Na Tabela 1 podemos verificar a proporção percentual dos grupos de veículos que transitaram nos pontos de amostragem. No grupo de veículos leves, todos os pontos são semelhantes, isso ocorre devido à cidade de Campo Mourão estar localizada em local estratégico no estado do Paraná, recebendo, então, uma grande frota destes. Os pontos A e D apresentaram semelhança no tráfego de veículos pesados por ambos estarem localizados em áreas de entroncamento rodoviário. Já os pontos $\mathrm{B}$ e $\mathrm{C}$ apresentaram 
dados parecidos por fazerem parte da área central da cidade, tendo, então, maior fluxo de veículos leves e consequentemente menor fluxo de veículos pesados devido à restrição de trânsito dos mesmos em alguns locais desta área do município, sendo autorizado somente o trânsito de camionetas, veículos de entrega de cargas e ônibus de transporte coletivo.

Tabela 1 - Valores percentuais da quantidade e classe de veículos nos pontos monitorados

\begin{tabular}{|l|l|l|l|l|l|}
\hline & Ponto A & Ponto B & Ponto C & Ponto D & Total \\
\hline Motocicletas & $24,5 \%$ & $15,0 \%$ & $18,6 \%$ & $19,2 \%$ & $20,2 \%$ \\
Veículos Leves & $60,1 \%$ & $77,8 \%$ & $74,7 \%$ & $66,8 \%$ & $68,3 \%$ \\
Veículos Pesados & $15,4 \%$ & $07,2 \%$ & $06,7 \%$ & $14,0 \%$ & $11,5 \%$ \\
\hline
\end{tabular}

A Figura 2 ilustra a semelhança entre as porcentagens dos veículos contabilizados nas amostragens em todos os pontos, com a quantidade de veículos registrados no município (Detran, janeiro 2014).

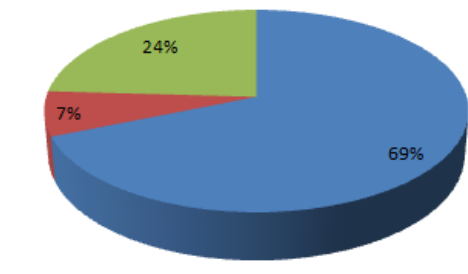

(A)

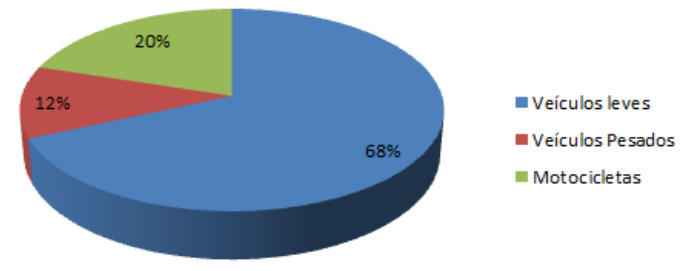

(B)

Figura 2 - Comparação dos dados do DETRAN/PR com o coletado no trabalho.

(A) dados obtidos no trabalho. (B) dados do DETRAN/PR (janeiro de 2014).

$\mathrm{O}$ aparelho detectou somente emissões de $\mathrm{CO}$, não havendo detecção de $\mathrm{H}_{2} \mathrm{~S}$ (ppm) e gases combustíveis (\%). Na estação da primavera os valores de temperatura e umidade do ar são maiores quando comparados aos do verão (Tabela 2).

Tabela 2 - Valores percentuais da quantidade e classe de veículos nos pontos monitorados

\begin{tabular}{|c|c|c|c|c|c|c|c|c|}
\hline & \multicolumn{4}{|c|}{ PRIMAVERA } & \multicolumn{4}{|c|}{ VERÃO } \\
\hline & \multicolumn{2}{|c|}{ Temperatura $\left(\mathrm{C}^{\circ}\right)^{*}$} & \multicolumn{2}{|c|}{$\begin{array}{l}\text { Umidade Relativa } \\
(\%) *\end{array}$} & \multicolumn{2}{|c|}{ Temperatura $\left(\mathrm{C}^{\circ}\right)^{*}$} & \multicolumn{2}{|c|}{$\begin{array}{c}\text { Umidade Relativa } \\
(\%)^{*}\end{array}$} \\
\hline Local & mínima & máximo & mínima & máximo & mínima & máximo & mínima & máximo \\
\hline Ponto A & 22,5 & 32,1 & $40,2 \%$ & $70,6 \%$ & 22,5 & 34,0 & $56,6 \%$ & $91,0 \%$ \\
\hline Ponto B & 21,8 & 32,9 & $37,7 \%$ & $68,1 \%$ & 21,0 & 34,2 & $46,1 \%$ & $80,0 \%$ \\
\hline Ponto C & 21,2 & 28,8 & $64,8 \%$ & $90,8 \%$ & 20,2 & 31,6 & $46,7 \%$ & $85,3 \%$ \\
\hline Ponto D & 21,5 & 33,6 & $36,8 \%$ & $66,8 \%$ & 23,3 & 35,0 & $44,0 \%$ & $77,2 \%$ \\
\hline
\end{tabular}

*Valores mínimos e máximos obtidos durante todo o dia. 
A figura 3 apresenta os valores da média horária de concentração de CO para todos os pontos de coleta de dados, compreendendo todos os horários.

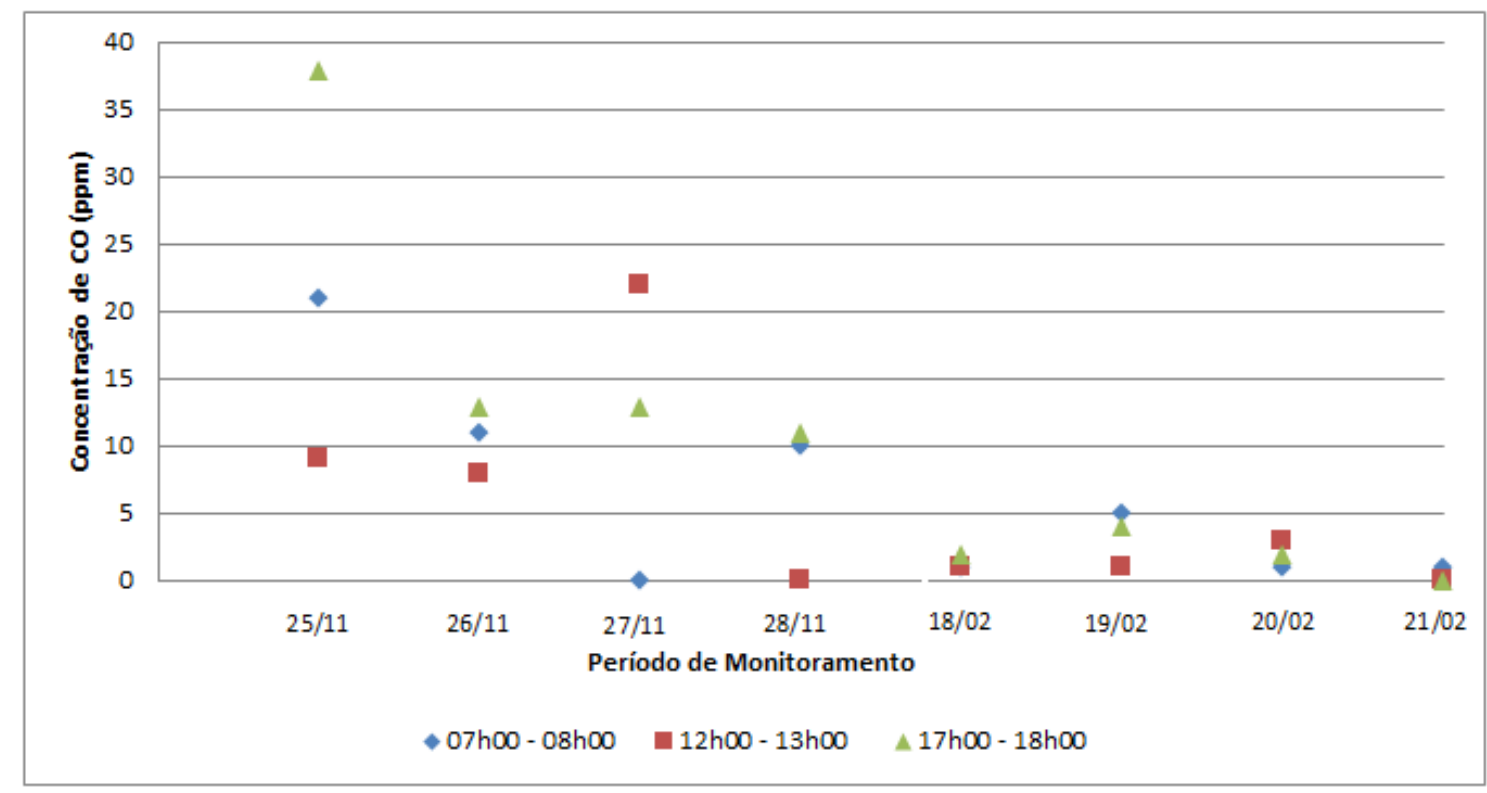

Figura 3 - Concentrações de CO na área urbana de Campo Mourão - PR, nos períodos de monitoramento.

No ponto A, dia 25/11/2013 nos horários das $07 \mathrm{~h} 00$ e $12 \mathrm{~h} 00$ observa-se que os valores médios de monóxido de carbono (CO) não ultrapassaram os $35 \mathrm{ppm}$ permitidos pelo CONAMA, como apresentado na Tabela 3. Porém no horário das $17 \mathrm{~h} 00$ a concentração média horária de $\mathrm{CO}$ foi de $38 \mathrm{ppm}$ de um total de 37 detecções nesse período. Para o dia 18/02/2014 os valores de CO foram semelhantes aos dados de novembro, apresentando valores abaixo dos permitidos pela legislação em todos os horários, porém no ultimo horário de coleta (17h00) em três detecções, o aparelho registrou um pico de $79 \mathrm{ppm}$. Nas duas datas o horário das $17 \mathrm{~h} 00$ era o mais movimentado em números de veículos pesados, o que explica os valores mais altos neste horário. Os veículos pesados geralmente são movidos ao combustível diesel, que é o mais poluente dos combustíveis fósseis utilizados em automóveis.

Tabela 3 - Concentração média horária de CO nos pontos monitorados em Campo Mourão - PR

\begin{tabular}{|l|l|l|l|l|l|l|l|l|}
\hline & \multicolumn{2}{|c|}{ PONTO A } & \multicolumn{2}{c|}{ PONTO B } & \multicolumn{2}{c|}{ PONTO C } & \multicolumn{2}{c|}{ PONTO D } \\
\cline { 2 - 8 } & $25 / 11$ & $18 / 02$ & $26 / 11$ & $19 / 02$ & $27 / 11$ & $20 / 02$ & $28 / 11$ & $21 / 02$ \\
\hline $07 \mathrm{~h} 00-08 \mathrm{~h} 00$ & $21 \mathrm{ppm}$ & $01 \mathrm{ppm}$ & $11 \mathrm{ppm}$ & $05 \mathrm{ppm}$ & $0 \mathrm{ppm}$ & $01 \mathrm{ppm}$ & $10 \mathrm{ppm}$ & $01 \mathrm{ppm}$ \\
\hline $12 \mathrm{~h} 00-13 \mathrm{~h} 00$ & $09 \mathrm{ppm}$ & $01 \mathrm{ppm}$ & $8 \mathrm{ppm}$ & $01 \mathrm{ppm}$ & $22 \mathrm{ppm}$ & $03 \mathrm{ppm}$ & $0 \mathrm{ppm}$ & $0 \mathrm{ppm}$ \\
\hline $17 \mathrm{~h} 00-18 \mathrm{~h} 00$ & $38 \mathrm{ppm}$ & $02 \mathrm{ppm}$ & $13 \mathrm{ppm}$ & $04 \mathrm{ppm}$ & $13 \mathrm{ppm}$ & $02 \mathrm{ppm}$ & $11 \mathrm{ppm}$ & $0 \mathrm{ppm}$ \\
\hline
\end{tabular}

No ponto B foram detectadas as maiores concentrações de $\mathrm{CO}$ entre todos os outros analisados. Para o dia 26/11/2013 os valores de CO não ultrapassaram os 35 ppm em nenhum dos três horários de coleta, porém às $12 \mathrm{~h} 00$ registrou-se um pico de 53 ppm. Este ponto faz parte da área central da cidade com presença de muitos edificios. Essas características que os centros urbanos vêm adotando de construir edificações elevadas interferem em um dos elementos climáticos cruciais para a dispersão dos poluentes, o vento. Os prédios formam uma espécie de corredor, onde os ventos são canalizados, o problema é que nem sempre a arquitetura da cidade acompanha a direção 
dos ventos podendo, por exemplo, impedir que as rajadas cheguem ao centro da cidade, reduzindo assim a dispersão dos poluentes. Outro problema é na dificuldade de os veículos se locomoverem no trânsito devido a intensa atividade comercial presente nesse ponto, fazendo com que os resultados apresentassem uma concentração máxima de 183 ppm de CO no dia 19/02/2014 no horário das 07h00. Neste ponto, como nos outros, ocorreram poucas detecções, com valores irrelevantes.

$\mathrm{O}$ ponto $\mathrm{C}$ apresentou, no verão, detecções parecidas com as do ponto B. No dia 27/11/2013 não registrou-se muitas detecções, e a média horária em todos os três horários ficou abaixo dos $35 \mathrm{ppm}$. As condições climáticas para este dia estava bem semelhantes ao do ponto $\mathrm{B}$, com poucas nuvens no céu e temperaturas mais amenas se comparadas aos dias anteriores. Para o episódio do verão (20/02/2014), os valores permaneceram abaixo dos permitidos, porém na coleta das $12 \mathrm{~h} 00$, houve pico de 90 ppm de CO nesse ponto. Na primavera (26/11/2013), os valores foram mais amenos por conta da temperatura e a umidade relativa do ar, que estavam mais elevadas.

$\mathrm{O}$ ponto $\mathrm{D}$ foi o que apresentou os menores valores de concentração de $\mathrm{CO}$, com apenas uma detecção em cada estação. Uma na primavera (28/11/2013), com concentração média horária de 10 ppm e outra no verão (21/02/2014), com 13 ppm, ambas no horário das $07 \mathrm{~h} 00$.

As médias horárias de concentração de $\mathrm{CO}$ foram maiores na estação da primavera, o que pode ser explicado pelas características climáticas atuantes nos dias de coleta, como a temperatura e umidade do ar que estavam menores se comparados aos dados do verão.

O tipo de combustível influencia na quantidade de poluentes emitidos, entre eles, os fósseis são os mais poluentes, por ser composto de matéria carbonada. Esses poluentes podem prejudicar a saúde da população e dos animais em concentrações acima de 4 ppm (partículas por milhão) oferecendo riscos à saúde, dependendo do tempo de exposição. Segundo Alves (2011) a gasolina e o diesel são combustíveis que poderiam ter uma combustão ideal se ocorressem em oxigênio puro, produzindo dióxido de carbono, vapor de água e energia. No entanto, no funcionamento dos motores há algumas emissões de combustível não queimado como os hidrocarbonetos e/ou combustível parcialmente queimado, emitindo óxido de nitrogênio, monóxido de carbono, material particulado, entre outros poluentes.

Todavia, o diesel libera cinco vezes mais $\mathrm{NO}_{x}$ e destaca-se com emissões de carbonilados de baixa massa molecular como formaldeído, acetaldeído e acetona. Além disso, os caminhões são os principais responsáveis pela liberação de material particulado (GUARIREIRO, VASCONCELLOS e SOLCI, 2011), mas também os veículos a diesel emitem mais Monóxido de Carbono comparado aos veículos à gasolina. De acordo com Braun, Appel e Schmal (2003) são utilizadas tecnologias como os filtros, catalisadores de oxidação e aditivos para a redução da emissão de poluentes.

A emissão de monóxido de carbono pelos veículos se dá por meio de reações químicas contendo matéria carbonada, entre elas a combustão incompleta $\left(2 \mathrm{C}+\mathrm{O}_{2} \rightarrow\right.$ $2 \mathrm{CO})$, combustão completa $\left(2 \mathrm{C}+\mathrm{O}_{2} \rightarrow 2 \mathrm{CO}_{2}\right)$ e por dissociação $\left(\mathrm{CO}_{2} \rightarrow \mathrm{CO}+\mathrm{O}\right)$, entre as reações citadas, a combustão incompleta é a principal responsável pelas emissões deste poluente.

Com o aumento dos centros urbanos há a necessidade de monitorar o "comportamento ambiental" dessas áreas a fim de obter informações sobre os problemas causados pelas alterações antrópicas. Vários estudos afirmam que problemas como desconforto térmico, inundações e alteração na qualidade do ar são decorrentes da falta do planejamento urbano. Segundo Amorim (2005), um planejamento urbano e ambiental bem elaborado associado a uma mudança de mentalidade da população local 
pode contribuir para uma cidade com condições ambientais melhores e consequentemente uma melhor qualidade de vida urbana para as pessoas. Além disso, o planejamento urbano possibilitaria a definição de rotas de tráfego das cidades, sistematizando-as para que os veículos consigam ir e vir com o menor tempo possível. Isso diminuiria os congestionamentos, e consequentemente nos poluentes lançados na atmosfera pelos veículos automotores, tendo o tempo de viagem reduzido.

A dinâmica atmosférica deve ser levada em consideração em qualquer estudo relacionado à dispersão de poluentes atmosféricos de uma maneira geral. Os sistemas atmosféricos que atuam na região, deslocamento dos sistemas frontais e das massas de ar definem as características climáticas e refletem diretamente no na dispersão dos poluentes.

Contudo segundo Franco et al. (2010) os estudos e pesquisas desenvolvidos no Brasil, na tentativa de minimizar os impactos desta urbanização sobre o meio ambiente, buscam como objetivo conhecer o funcionamento do complexo sistema climático urbano, no qual estão envolvidas inúmeras variáveis microclimáticas, tendo em vista que há ainda uma grande variação comportamental de região para região. Conhecendo melhor o sistema climático de cada região pode-se entender o comportamento dos poluentes nas várias situações climáticas. O espaço urbano precisa de muita atenção, pois é nele que muitas pessoas moram e os problemas que vêm acontecendo são resultados de várias décadas de uso desses ambientes sem dar a devida atenção às necessidades naturais do mesmo.

\section{CONCLUSÃO}

Com os métodos utilizados no trabalho foi possível perceber que a concentração do monóxido de carbono ( $\mathrm{CO}$ ) no ar não é determinada apenas pela quantidade de veículos que trafegam, mas também pelo estado de manutenção dos mesmos. Constatou-se também que a maior parte dos picos acima do valor máximo permitido pela legislação ocorreu quando os veículos de modelos antigos trafegavam pelo local. Os veículos mais novos, tanto leves quanto os pesados, agregaram tecnologias que reduzem a emissão de poluentes, como o uso de novos catalisadores, em conformidade com a Resolução CONAMA n ${ }^{\circ}$ 18, de 06 de junho de 1986, que dispõe sobre a criação do Programa de Controle de Poluição do Ar por veículos Automotores - PROCONVE.

A temperatura, umidade relativa do ar e localização dos pontos das coletas também são fatores de grande influência na detecção dos poluentes. Também verificouse que o aspecto geográfico dos pontos interfere na dispersão dos gases, pois dois dos locais selecionados estavam localizados na área central do município, com maior concentração de residências, prédios elevados e pontos comerciais.

As condições climáticas podem provocar fenômenos naturais que dificultam a dispersão dos poluentes. Conforme a temperatura se elevava ao longo do dia, o movimento de convecção da atmosfera auxiliava a sua dispersão, demonstrado pela constatação de menor quantidade de picos e detecções no período das $12 \mathrm{~h} 00$ às $13 \mathrm{~h} 00$.

A tabulação de dados relativos ao monitoramento da qualidade do ar em regiões do município de Campo Mourão pode estimular a sua aplicação no desenvolvimento de novos empreendimentos na cidade, mostrando o grau de poluição existente e o comprometimento do meio científico composto pelas universidades, e da comunidade em geral na procura de soluções que favoreçam o desenvolvimento sustentável. Os resultados pretendem conscientizar os administradores públicos sobre a necessidade de 
quantificar os valores das emissões atmosféricas, promovendo discussões sobre ações preventivas.

Os dados obtidos com o monitoramento e a quantificação do grau de poluição de cada segmento de automóveis e sua participação no volume geral de emissões, principalmente de monóxido de carbono e hidrocarbonetos voláteis, pode servir de base para ações municipais visando policiar o fluxo de veículos em determinados locais do município e os horários mais compatíveis, evitando o acúmulo de grandes concentrações de poluentes nessas áreas e horários. Os dados podem também servir de orientação aos motoristas, indústrias e empresas donas de frotas de veículos com relação à manutenção dos automóveis, ônibus e caminhões, proporcionando um alerta para a revisão periódica dos filtros, catalisadores e outros equipamentos dos veículos.

\section{REFERÊNCIAS}

ALVES, A. da C. E. Contribuição das emissões de poluentes de veículos para a poluição atmosférica urbana. 2011.131f, Dissertação (Mestrado em Engenharia Automóvel) - Escola Superior de Tecnologia e Gestão, Instituto Politécnico de Leiria, 2011.

AMORIM, M.C.C.T., VIANA, S.S.M. O Clima Urbano em Teodoro Sampaio/SP: episódios de Verão; Revista brasileira de Climatologia, p.41-54, setembro 2005. São Paulo - SP.

BRASIL, Resolução CONAMA nº 003 de 28 de junho de 1990. Diário Oficial [da] República Federativa do Brasil. Poder Executivo, Brasília, DF, 22 ago. 1990.

BRAUN, Silvana. ; APPEL G. Lucia.; SCHMAL Martin. A poluição gerada por máquinas de combustão interna à Diesel - A questão dos particulados. Estratégias atuais para a redução e controle das emissões e tendências futuras. Química Nova. Rio de Janeiro, v.27, n.3,p. 472-282, 2003.

DETRAN. Detran Paraná, dados estatísticos. Disponivel em: $<$ http://www.detran.pr.gov.br/modules/conteudo/conteudo.php? conteudo=194>. Acesso em 02 Abr. 2014.

FRANCO, F.M. et al. Clima Urbano: Um Estudo De Caso Para Clima Tropical Continental; CLIMEP - Climatologia e Estudos da Paisagem, Vol. 5 - n.1, p.81- 99, janeiro/junho. 2010, Rio Claro - SP, 2010.

GUARIREIRO, L. L. N; VASCONCELlOS, P. C.; SOLCI, M. C. Poluentes Atmosféricos Provenientes da Queima de Combustíveis Fósseis e Biocombustíveis: Uma Breve Revisão. Virtual Química.;v.3, n.5, p.434-445, 2011.

IBGE, Instituto Brasileiro de Geografia e Estatística. Estimativa da População para 2013. Disponível em: < http://www.cidades.ibge.gov.br/xtras/perfil.php?lang $=\&$ codmun $=410430 \&$ search $=$ par ana|campo-mourao>. Acesso em 02 Abr. de 2014.

MANZOLI, A. Análise das Emissões Veiculares em Trajetos Urbanos Curtos com Localização por GPS. 2009, 200p. Tese (Doutorado em Engenharia Civil). Universidade de São Paulo, São Carlos, 2009. 